\title{
Increased Urinary Interleukin 22 Binding Protein Levels Correlate with Lupus Nephritis Activity
}

\author{
Xuyan Yang, Yin Gao, Huiying Wang, Xiaoying Zhao, Xubo Gong, Qingqing Wang, \\ and Xiaofei Zhang
}

ABSTRACT. Objective. Interleukin 22 (IL-22) plays an important role in the promotion of antimicrobial immunity. However, dysregulated IL-22 action leads to inflammation and is involved in autoimmune diseases, including systemic lupus erythematosus (SLE). IL-22 binding protein (IL-22BP) is a soluble inhibitory IL-22 receptor and may represent a crucial regulator of IL-22. We investigated the expression and potential significance of serum and urinary IL-22BP levels in patients with SLE. Methods. A total of 112 patients with SLE and healthy control subjects participated in our study. Patients were classified according to kidney involvement and disease activity based on clinical and laboratory measures such as urinary sediment, proteinuria, kidney function, complement factor 3 (C3), C4, anti-dsDNA, disease activity index, and renal SLE disease activity index. The concentrations of IL-22BP and IL-22 were measured by ELISA. The expression of IL-22BP in the renal tissue was detected by immunohistochemistry.

Results. Patients with active renal disease had urinary levels of IL-22BP higher than (1) patients with active SLE but no renal involvement, (2) patients with a history of lupus nephritis in remission with no systemic disease activity and no history of renal involvement, and (3) control subjects. There was no difference in serum levels of IL-22BP among the groups. Urinary levels of IL-22BP in patients with active renal disease were positively correlated with SLE Disease Activity Index, Systemic Lupus International Collaborating Clinics renal activity score, and histological activity index. IL-22BP was highly expressed in renal tissue of patients with active renal disease. After 6 months of treatment, urinary IL-22BP levels decreased significantly in patients with complete response, but remained unchanged in those with partial or no response.

Conclusion. Urinary but not serum IL-22BP levels were associated with active renal disease. Urinary levels of IL-22BP might be a potential marker for the presence of renal involvement in patients with SLE. (First Release Aug 1 2014; J Rheumatol 2014;41:1793-800; doi:10.3899/ jrheum.131292)

\section{Key Indexing Terms:} SYSTEMIC LUPUS ERYTHEMATOSUS RENAL ACTIVITY

Systemic lupus erythematosus (SLE) is a prototypical systemic autoimmune disorder characterized by hyperglobulinemia, autoantibody production, and multiorgan involvement, which commonly affects the kidney ${ }^{1}$. The intricate involvement of inflammatory mediators including cytokines

From the Department of Rheumatology, Second Affiliated Hospital, College of Medicine, and Department of Immunology, Institute of Basic Medical Sciences, College of Medicine, Zhejiang University, Hangzhou, Zhejiang, China.

Supported by the Science Foundation of Science and Technology Department of Zhejiang Province.

X.Y. Yang, MD; Y. Gao, MD, Department of Rheumatology; H.Y. Wang, $M D, P h D$, Department of Allergy and Clinical Immunology; X.Y. Zhao, MD, Department of Hematology; X.B. Gong, MD, Laboratory of Bone Marrow, Second Affiliated Hospital, College of Medicine, Zhejiang University; Q.Q. Wang, MD, PhD, Department of Immunology, Institute of Basic Medical Sciences; X.F. Zhang, MD, Department of Clinical Epidemiology and Biostatistics, Second Affiliated Hospital, College of Medicine, Zhejiang University.

Address correspondence to Dr. X.Y. Zhao, Department of Hematology, Second Affiliated Hospital, College of Medicine, Zhejiang University, 88 Jiefang Road, Hangzhou, Zhejiang, 310009, People's Republic of China. E-mail:zrxz@zju.edu.cn

Accepted for publication April 25, 2014.

\section{INTERLEUKIN-22 LUPUS NEPHRITIS} IL-22 BINDING PROTEIN

seems fundamental in the aberrant immune system of $\mathrm{SLE}^{2,3}$. Traditionally, the imbalance in the cytokines produced by the 2 subsets of Th cells, Th1 and Th2, is believed to play an important role in the pathogenesis of $\mathrm{SLE}^{4}$.

Research has revealed a novel cytokine of the interleukin 10 (IL-10) family: IL-22, which is mainly produced by Th cells, such as Th17 and Th22, and innate lymphoid cells ${ }^{5,6,7}$. The membrane-bound IL-22 receptor1 (IL-22R1, IL-22RA1) is absent on immune cells, but expressed within tissues, such as the epithelial cells of the skin, gastro-intestinal system, and kidney ${ }^{8}$. IL-22 has an important function in the promotion of antimicrobial immunity through induction of antimicrobial peptides, and in tissue repair through induction of epithelial cell proliferation and survival ${ }^{9,10,11}$. However, it can also promote pathological inflammatory responses through induction of production of inflammatory cytokines, such as IL-6, IL-1 $\alpha$, and IL-10 12,13 . Concentration of IL-22 is increased in a variety of human diseases including psoriasis, rheumatoid arthritis, infections, and inflammatory bowel diseases ${ }^{5}$. However, the role of

Personal non-commercial use only. The Journal of Rheumatology Copyright $@$ $\odot 2014$. All rights reserved. 
IL-22 in SLE needs to be clarified because the situation of IL-22 in the peripheral blood of patients with SLE is more controversial: either decreased or unchanged IL-22 levels have been reported ${ }^{14,15}$.

IL-22BP is a soluble IL-22 receptor that lacks a transmembrane and intracellular domain. IL-22BP is expressed in the epithelium and various mononuclear cells, and various tissues including the breast, lungs, and colon ${ }^{16,17,18}$. It can be upregulated in macrophages following exposure to lipopolysaccharide ${ }^{16}$. IL-22BP specifically binds to IL-22 but not other IL-10 family members, and prevents the binding of IL-22 to membrane-bound IL-22R $1^{17,18}$. The binding of IL-22 to IL-22BP is of 20 -fold to 1000 -fold higher affinity compared to its binding to the membrane-bound IL-22R1, and therefore IL-22BP acts as a natural cytokine antagonist ${ }^{18}$. Some studies showed that the expression of IL-22BP was dynamically regulated during infections and colitis ${ }^{9,19,20}$. Wilson, et al found the levels of IL-22BP were increased when IL-22 was downregulated in the liver of mice after infection with Schistosoma mansoni or Mycobacterium avium and Toxoplasma gondii, respectively ${ }^{19}$.

Our previous study showed decreased serum levels of IL-22 in SLE patients with renal involvement ${ }^{15}$. However, the expression of IL-22BP in patients with SLE is unclear. In the current study, we investigated the expression and potential significance of serum and urinary IL-22BP levels in patients with SLE.

\section{MATERIALS AND METHODS}

Patients and controls. Our cross-sectional study was approved by the ethical committee of the hospital and carried out at the Department of Rheumatology of the Second Affiliated Hospital, Zhejiang University. We prospectively recruited 112 patients with SLE attending rheumatology clinics from April 2011 to December 2012. All signed approved informed consent. All patients fulfilled the American College of Rheumatology (ACR) diagnostic criteria of SLE ${ }^{21}$. SLE Disease Activity Index (SLEDAI) was used to determine the global disease activity 22 . Active SLE was defined by $S L E D A I \geq 6^{23,24}$. Complicated lupus nephritis (LN) was defined according to ACR criteria, i.e., any 1 of the following: (1) persistent proteinuria $\geq 0.5 \mathrm{~g} / \mathrm{day}$; (2) the presence of active cellular casts; or (3) biopsy evidence of $\mathrm{LN}^{25}$. We also recruited 20 healthy volunteers as controls.

Clinical and laboratory data. Patient records were reviewed while renal activity was assessed. According to ACR criteria, systemic analysis focusing on renal and extrarenal manifestations was undertaken. Serologic data included complement factor 3 (C3), C4, anti-dsDNA, and antinuclear antibody. We used the Systemic Lupus International Collaborating Clinics (SLICC) Renal Activity Score to quantify renal disease activity ${ }^{26}$. It is calculated as follows: proteinuria 0.5 to $1 \mathrm{~g} /$ day ( 3 points), proteinuria 1 to $3 \mathrm{~g} /$ day ( 5 points), proteinuria $>3 \mathrm{~g} /$ day (11 points), urine red blood cells $\geq$ 5/high power field (hpf; 3 points), and urine white blood cells $\geq 5 / \mathrm{hpf}$ ( 1 point). Renal activity scores range from 0 (inactive renal disease) to maximum of $16^{27}$.

Clinical management and evaluation. We followed patients with active SLE and renal involvement (active renal disease) for 6 months. The clinical management was determined depending on disease activity at each visit. In general, patients with active renal disease were treated with corticosteroid, together with cyclophosphamide or mycophenolate according to published protocols ${ }^{28}$. After 6 months of treatment, therapeutic response was assessed and classified into complete remission, partial remission, and no response ${ }^{28}$. Briefly, complete response was defined as a value for urinary protein excretion that was $<0.3 \mathrm{~g} / \mathrm{g}$ creatinine, with normal urinary sediment, a normal serum albumin concentration, and values for both serum creatinine and creatinine clearance that were $15 \%$ or less above the baseline values. Partial response was defined as a value for urinary protein excretion that was between 0.3 and $2.9 \mathrm{~g} / \mathrm{g}$ creatinine, with a serum albumin concentration of at least $30 \mathrm{~g} / \mathrm{dl}$ and stable renal function. No response was defined as a value for urinary protein excretion that remained at a value of $\geq 3 \mathrm{~g} / \mathrm{g}$ creatinine or a value of $0.3-2.9 \mathrm{~g} / \mathrm{g}$ creatinine, but with a serum albumin value of $<30 \mathrm{~g} / \mathrm{dl}$, an increase in the serum creatinine concentration $\geq 50 \mu \mathrm{mol} / 1$, a value for creatinine clearance that was more than $15 \%$ above the baseline value, or the discontinuation of treatment owing to side effects.

Serum and urine collection, preparation, and biomarker measurement. On the day of clinical assessment, serum and urine samples were collected. Fasting blood was collected by venipuncture, and serum was immediately prepared, aliquoted, and stored at $-80^{\circ} \mathrm{C}$ until time of assay. Urine "clean-catch midstream" samples were collected into appropriate sterile containers and placed on ice or refrigerated at $4^{\circ} \mathrm{C}$ within $1 \mathrm{~h}$ of collection. Aliquots and the remaining urine samples in the centrifuge tube were frozen at $-80^{\circ} \mathrm{C}$ until assay. Serum and urinary concentrations were measured by ELISA for IL-22BP (Abcam) and IL-22 (R\&D Systems). The results of serum data were reported as $\mathrm{pg} / \mathrm{ml}$, and urinary data were standardized to urine creatinine measured from the same spot urine and expressed as $\mathrm{pg} / \mathrm{mgCr}$. For IL-22BP, intercoefficient and intracoefficient of variation $(\mathrm{CV})$ were $<10.2 \%$. For IL-22, inter- and intra-CV was less than $15 \%$ and $9 \%$, respectively.

Histological assessment. At the time of blood collection, kidney biopsy was also conducted in patients with active renal disease. The kidney biopsy specimens were evaluated according to the International Society of Nephrology pathologic classification of $\mathrm{LN}^{29}$. For each specimen, the histological activity index and chronicity index were scored by standard methods ${ }^{29,30}$. All biopsy specimens were evaluated by a single pathologist, who was blinded to the results of the SLEDAI score, and blood and urine tests. Immunohistochemistry stainings were carried out with monoclonal antibodies directed against IL-22BP (Abcam).

Statistical analysis. Statistical analysis was performed by Statistical Package for Social Sciences version 17.0 software (SPSS). Comparison between groups was calculated using Kruskal-Wallis test or Mann-Whitney $\mathrm{U}$ test as appropriate. Because the data of IL-22BP and IL-22 were mostly not normally distributed, they were presented in terms of median with interquartile range, which represents central tendency and spread. Changes in IL-22BP levels before and after treatment were compared by the Wilcoxon rank-sum test. Correlations of IL-22BP levels with the SLEDAI scores, renal activity scores, and biochemical variables were determined by Spearman's rank correlation coefficient denoted as $r_{s}$, which is a nonparametric measure of statistical dependence between 2 variables. It assesses how well the relationship between 2 variables can be described using a monotone function. If there are no repeated data values, a perfect Spearman correlation of +1 or -1 occurs when each of the variables is a perfect monotone function of the other ${ }^{31}$. A $p$ value of $<0.05$ was considered statistically significant. All probabilities were 2 -tailed.

\section{RESULTS}

Demographic and baseline clinical data. One hundred twelve patients with SLE were classified into 4 groups: 27 consecutive patients with active lupus and renal involvement (Active Renal Disease), 30 patients with active lupus but no renal involvement (Active But No Renal Disease), 25 patients with a history of LN whose disease became quiescent for at least 6 months after treatment (Renal

Personal non-commercial use only. The Journal of Rheumatology Copyright @ $\subset$ 2014. All rights reserved. 
Disease in Remission), and 30 patients without systemic disease activity and with no history of renal disease (Neither Active Nor Renal Disease); 20 healthy volunteers as controls were included. More details of demographic and baseline clinical data are shown in Table 1.

Serum and urinary IL-22BP between groups. Comparison of serum and urinary levels of IL-22BP between Active Renal Disease, Active But No Renal Disease, Renal Disease in Remission, Neither Active Nor Renal Disease, and controls are shown in Table 2. Because of skewed data, the data were log-transformed and analyzed. The results are shown in Figure 1. Significantly higher concentrations of urinary IL-22BP were found in Active Renal Disease versus the other groups $(\mathrm{p}<0.001$; Table 2 and Figure 1B). Among other groups, no significant differences in urinary levels of IL-22BP were found.
There was no significant difference in serum levels of IL-22BP among the groups.

Correlation of serum $I L-22 B P$ and urinary $I L-22 B P$. No significant correlation was observed between levels of serum and urinary IL-22BP in any of the groups, particularly in the Active Renal Disease ( $\mathrm{r}=0.017$, $\mathrm{p}=0.781$ ).

Levels of IL-22 and its correlation with IL-22BP. Levels of serum IL-22 in the Active Renal Disease group were significantly decreased versus those in the Active But No Renal Disease group, the Renal Disease in Remission group, the Neither Active Nor Renal Disease group, and in controls $(\mathrm{p}<0.01$; Table 2 and Figure 1C). However, serum IL-22 presented no correlation with serum IL-22BP in any of the groups, particularly in the Active Renal Disease ( $r=0.137$, $p=0.602)$. Because of very low levels of urinary IL-22 in

Table 1. Demographic and baseline clinical data. Data shown are expressed as mean \pm SD. Data are compared by chi-square test or 1-way ANOVA.

\begin{tabular}{|c|c|c|c|c|c|}
\hline Characteristics & $\begin{array}{l}\text { Active Renal } \\
\text { Disease }\end{array}$ & $\begin{array}{l}\text { Active But No } \\
\text { Renal Disease }\end{array}$ & $\begin{array}{l}\text { Renal Disease in } \\
\text { Remission }\end{array}$ & $\begin{array}{l}\text { Neither Active } \\
\text { Nor Renal Disease }\end{array}$ & Controls \\
\hline No. patients & 27 & 30 & 25 & 30 & 20 \\
\hline Age, yrs & $37.2 \pm 7.6$ & $36.8 \pm 8.2$ & $37.8 \pm 9.5$ & $38.2 \pm 6.5$ & $36.4 \pm 8.2$ \\
\hline Serum albumin, $\mathrm{g} / \mathrm{dl}$ & $21.0 \pm 5.7 * *$ & $37.3 \pm 6.7$ & $38.2 \pm 7.2$ & $36.8 \pm 5.9$ & $40.2 \pm 8.2$ \\
\hline Serum creatinine, $\mu \mathrm{mol} / 1$ & $85.5 \pm 27.2$ & $87.2 \pm 23.4$ & $91.3 \pm 30.2$ & $86.4 \pm 28.5$ & $90.3 \pm 32.6$ \\
\hline Anti-dsDNA titer & $432.1 \pm 310.6^{* *}$ & $173.9 \pm 102.1^{\#}$ & $187.4 \pm 192.1^{\$}$ & $43.2 \pm 32.7$ & 0 \\
\hline $\mathrm{C} 3 \mathrm{~g} / 1$ & $0.57 \pm 0.47$ & $0.70 \pm 0.51$ & $0.62 \pm 0.47$ & $0.87 \pm 0.37$ & $1.42 \pm 0.41^{*}$ \\
\hline $\mathrm{C} 4 \mathrm{~g} / \mathrm{l}$ & $0.14 \pm 0.11$ & $0.13 \pm 0.10$ & $0.13 \pm 0.09$ & $0.16 \pm 0.12$ & $0.19 \pm 0.10$ \\
\hline SLEDAI score & $13.1 \pm 4.2^{*}$ & $10 \pm 2.7^{\# \#}$ & $2.05 \pm 1.0$ & $0 \pm 0$ & \\
\hline Renal activity score & $7.4 \pm 3.7 * *$ & $0 \pm 0$ & $0 \pm 0$ & $0 \pm 0$ & \\
\hline
\end{tabular}

**p $<0.0001$ for Active Renal Disease vs Active But No Renal Disease, Renal Disease in Remission, Neither Active Nor Renal Disease, and controls; * $<$ 0.0001 for Active Renal Disease vs Renal Disease in Remission, Neither Active Nor Renal Disease, and controls; ${ }^{\#} \mathrm{p}<0.0001$ for Active But No Renal Disease vs Renal Disease in Remission, Neither Active Nor Renal Disease, and controls; ${ }^{\#} \mathrm{p}<0.0001$ for Active But No Renal Disease versus Neither Active Nor Renal Disease and controls; ${ }^{\$} \mathrm{p}<0.0001$ for Renal Disease in Remission vs Neither Active Nor Renal Disease and controls, ${ }^{*} \mathrm{p}<0.001$ for controls versus Active Renal Disease, Active But No Renal Disease, Renal Disease in Remission, Neither Active Nor Renal Disease. GFR: glomerular filtration rate; Active Renal Disease: patients with active SLE and renal involvement; Active But No Renal Disease: patients with active SLE but no renal involvement; Renal Disease in Remission: patients with history of lupus nephritis in remission; Neither Active Nor Renal Disease: patients without systemic disease activity and with no history of renal disease; SLE: systemic lupus erythematosus; C3: complement factor 3; SLEDAI: SLE Disease Activity Index.

Table 2. The concentration of interleukin 22 BP (IL-22BP) and IL-22 in different groups. Data are median (IQR).

\begin{tabular}{lccc}
\hline Groups & $\begin{array}{c}\text { Serum IL-22BP, } \\
\mathrm{pg} / \mathrm{ml}\end{array}$ & $\begin{array}{c}\text { Urinary IL-22BP, } \\
\mathrm{pg} / \mathrm{mgCr}\end{array}$ & $\begin{array}{c}\text { Serum IL-22, } \\
\mathrm{pg} / \mathrm{ml}\end{array}$ \\
\hline Active Renal Disease & $89.7(65-154)$ & $156(112-210)^{*}$ & $101.2(77.3-167.6)^{* *}$ \\
Active But No Renal Disease & $107(67-156.5)$ & $64(37.8-90)$ & $202(89.5-306.2)$ \\
Renal Disease in Remission & $113(67-167.5)$ & $63(39.5-88)$ & $201(114-242.9)$ \\
Neither Active Nor Renal Disease & $102(67-157.5)$ & $52(35-76.5)$ & $172.5(109-239.9)$ \\
Controls & $104(47.5-153.8)$ & $44(34.3-68.5)$ & $209.5(107.8-272.9)$
\end{tabular}

$* \mathrm{p}<0.001 ; * * \mathrm{p}<0.01 . \mathrm{IQR}$ : interquartile range; Active Renal Disease: patients with active lupus and renal involvement; Active But No Renal Disease: patients with active lupus but no renal involvement; Renal Disease in Remission: patients with history of lupus nephritis in remission; Neither Active Nor Renal Disease: patients without systemic disease activity and with no history of renal disease. 
A

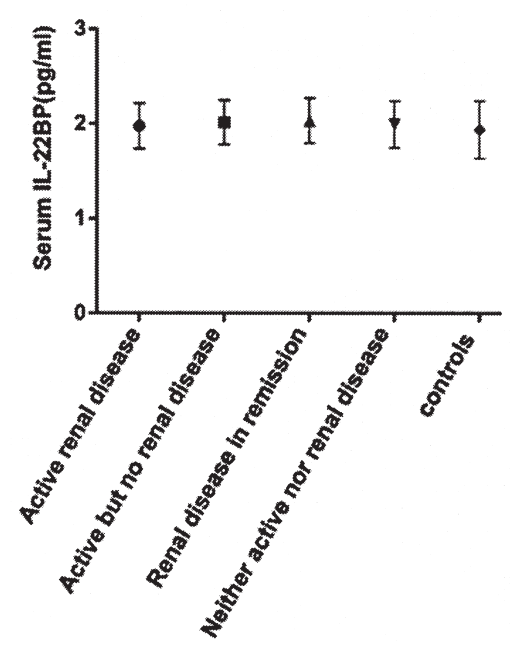

B

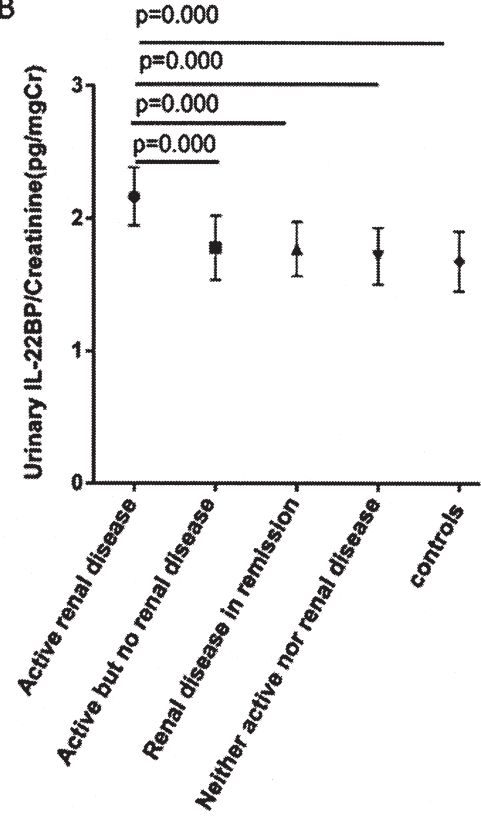

C

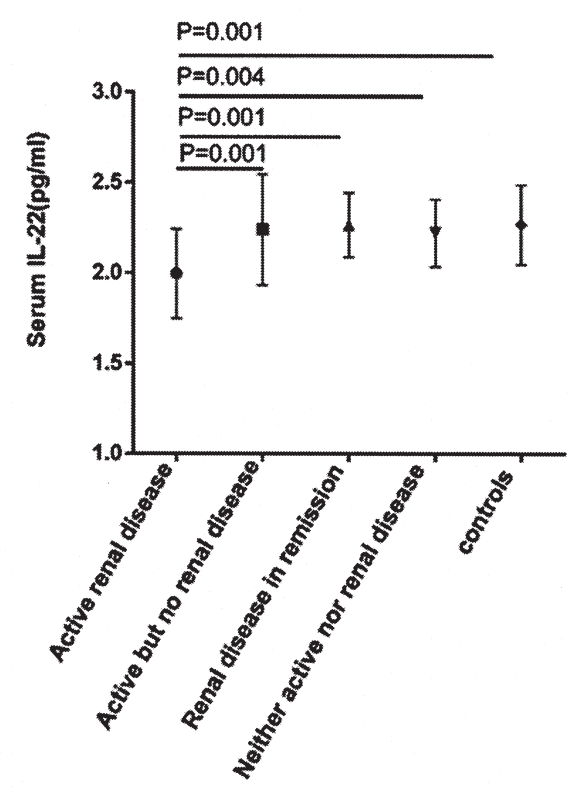

Figure 1. Comparison of concentrations of interleukin 22BP (IL-22BP) and IL-22 in different groups after data were log-transformed. A. Levels of serum IL-22BP showed no significant difference among patients with active lupus and renal involvement (Active Renal Disease group), with active systemic lupus erythematosus but no renal involvement (Active But No Renal Disease), with a history of lupus nephritis whose disease became quiescent for at least 6 months after treatment (Renal Disease in Remission), and without systemic disease activity and no history of renal disease (Neither Active Nor Renal Disease), and controls. B. Significantly higher concentrations of urinary IL-22BP were present in the Active Renal Disease group versus those in the Active No Renal Disease, Renal Disease in Remission, Neither Active Nor Renal Disease, and controls. C. Levels of serum IL-22 in the Active Renal Disease group were significantly decreased compared with those in the Active No Renal Disease, Renal Disease in Remission, Neither Active Nor Renal Disease, and in controls .

A

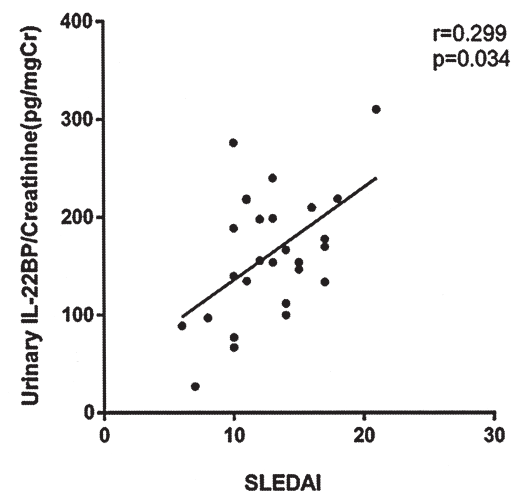

C

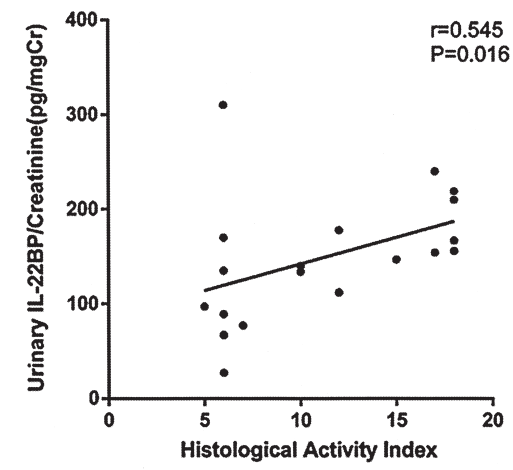

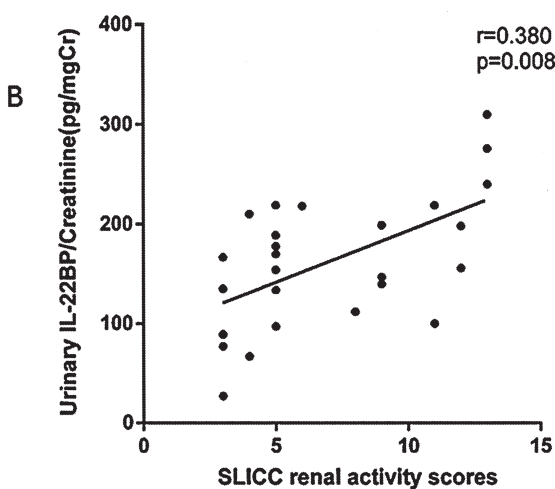

Figure 2. Correlation between interleukin 22BP (IL-22BP) levels in urine from patients with systemic lupus erythematosus (SLE) and indices of SLE disease activity. A. Levels of urinary IL-22BP in patients with active lupus and renal involvement (Active Renal Disease) showed a weak correlation with SLE Disease Activity Index (SLEDAI) scores. B. A stronger correlation was found between levels of urinary IL-22BP and Systemic Lupus International Collaborating Clinics (SLICC) renal activity scores in the Active Renal Disease group. C. A correlation was found between levels of urinary IL-22BP and histological activity index findings of renal biopsy in the Active Renal Disease group. Results for IL-22BP are expressed as picograms of urinary IL-22BP per $\mathrm{mg}$ of creatinine $(\mathrm{pg} / \mathrm{mgCr}$ ). 
patients with SLE and controls that could not be detected, those data were not analyzed.

Urinary IL-22BP and SLE disease activity. Urinary IL-22BP had a significant but weak association with the SLEDAI $(r=0.299, p=0.034)$ in Active Renal Disease (Figure 2A). However, a correlation of urinary IL-22BP with SLEDAI was not found in groups Active But No Renal Disease ( $\mathrm{r}=$ $0.155, \mathrm{p}=0.254)$, Renal Disease in Remission ( $\mathrm{r}=0.113$, $\mathrm{p}=0.946)$, and Neither Active Nor Renal Disease ( $\mathrm{r}=$ $0.107, \mathrm{p}=0.976$ ). An association between levels of urinary IL-22BP and dsDNA antibody was not observed in Active Renal Disease $(r=0.363, p=0.312)$. Serum C3 and C4 values in the Active Renal Disease did not show a significant correlation with urinary IL-22BP levels $(r=0.207, p=$ $0.422 ; \mathrm{r}=0.163, \mathrm{p}=0.816$, respectively).

Urinary IL-22BP and renal disease activity. A stronger positive correlation was found between levels of urinary IL-22BP and SLICC renal activity score in Active Renal Disease $(r=0.380, p=0.008$; Figure $2 B)$. No significant correlation between proteinuria and urinary IL-22BP levels was found in the Active Renal Disease $(r=0.271, p=$ 0.172). To further confirm that the elevation of urinary IL-22BP observed in patients with Active Renal Disease was due to increased local production rather than to non-specific loss of filtered protein, we removed the proteinuria component from SLICC renal activity scores and reanalyzed the data. In Active Renal Disease, there was a significant correlation of urinary IL-22BP with SLICC renal activity scores $(r=0.464, p=0.025)$, even after exclusion of proteinuria from the scores.

Urinary IL-22BP and histological features. Renal biopsy from 19 patients with active renal disease showed diffuse proliferative LN (Class IV, 13 cases), pure membranous disease (Class V, 3 cases), pure focal glomerulonephritis (Class III, 1 case), and mixed diffuse proliferative and membranous disease (2 cases). Urinary IL-22BP correlated with the histological Activity Index of the kidney biopsy $(r=0.545, p=0.016$; Figure 2C). No urinary IL-22BP findings correlated with the histological Chronicity Index, degree of glomerulosclerosis, or tubulointerstitial fibrosis (details not shown). Immunohistochemistry showed high expression of IL-22BP in the renal tissue of patients with active renal disease (Figure 3).

Serum IL-22BP and disease activity indices. Serum IL-22BP levels did not correlate with SLEDAI or SLICC renal activity scores in any of the groups, particularly in Active Renal Disease $(r=0.171, p=0.726 ; r=0.211, p=$ 0.682 , respectively).

Relation with treatment response. After 6 months of treatment, 17 patients with active renal disease had complete response to treatment, 8 patients had partial response, and 2 patients had no response. In patients with complete response, the SLICC renal activity scores significantly decreased (from $6.29 \pm 3.06$ to $1.10 \pm 1.18 ; \mathrm{p}=0.000$ ), and urinary levels of IL-22BP significantly decreased (from $166.29 \pm 59.57$ to $92.0 \pm 40.12 ; \mathrm{p}=0.001$; Figure 4). By contrast, the SLICC renal activity scores and urinary levels of IL-22BP remained unchanged in patients with partial or no response (from $6.60 \pm 3.56$ to $5.10 \pm 2.07, \mathrm{p}=2.13$; and from $154.50 \pm 69.54$ to $134.0 \pm 59.03 ; \mathrm{p}=0.635$, respectively).

\section{DISCUSSION}

IL-22BP acts as a natural regulator of IL-22, preventing exaggerated effects of the cytokine. Our previous study presented decreased serum IL-22 in patients with $\mathrm{LN}^{15}$. To detect whether the expression of IL-22BP might be regulated, which in turn would affect levels of IL-22 in LN, we examined the expression of IL-22BP in serum and urine of patients with SLE. Our results showed that urinary IL-22BP was significantly higher in patients with active renal disease versus normal controls and other SLE groups. However, there was no statistically significant difference in the levels of serum IL-22BP or between serum and urinary levels of IL-22BP among the groups. The levels of urinary IL-22 are very low in both SLE patients and controls. Moreover, we found high expression of IL-22BP in renal tissue of patients with active renal disease.

It is well established that longterm survival in SLE can be improved with early diagnosis and prompt treatment of renal disease ${ }^{32}$. However, the usually insidious onset and fluctuating nature of LN can make early identification and followup very difficult. While renal biopsy is the gold standard for diagnosis and assessment of LN, it is an invasive procedure that is not generally performed serially for monitoring purposes. Anti-dsDNA antibodies and complement levels are routinely followed in patients with $\mathrm{SLE}^{33,34,35}$. However, while often correlating with the presence of active renal disease, these serologic variables are not specific for this manifestation and their performance as nephritis biomarkers is not optimal. Routine laboratory tests reflecting renal function, such as urinalysis, urinary protein measurements, blood urea nitrogen, and serum creatinine are useful in monitoring chronic renal processes, but abnormal levels may occur relatively late in the inflammatory course. A reliable clinical biomarker for $\mathrm{LN}$ needs to be further explored.

In our study, we found that urinary levels of IL-22BP in patients with active renal disease were weakly correlated with disease activity as measured by SLEDAI, although the correlation with SLICC renal activity score was stronger. In the 19 patients with a renal biopsy, there was a correlation with urinary IL-22BP and disease activity index. We did not find a correlation of urinary protein excretion and urinary IL-22BP levels, further suggesting that elevated levels may reflect kidney production of IL-22BP rather than simply another marker of proteinuria. Taken together, our results suggest that urinary IL-22BP might be a useful biomarker for LN and may reflect kidney production of IL-22BP.

Personal non-commercial use only. The Journal of Rheumatology Copyright (c) 2014. All rights reserved. 

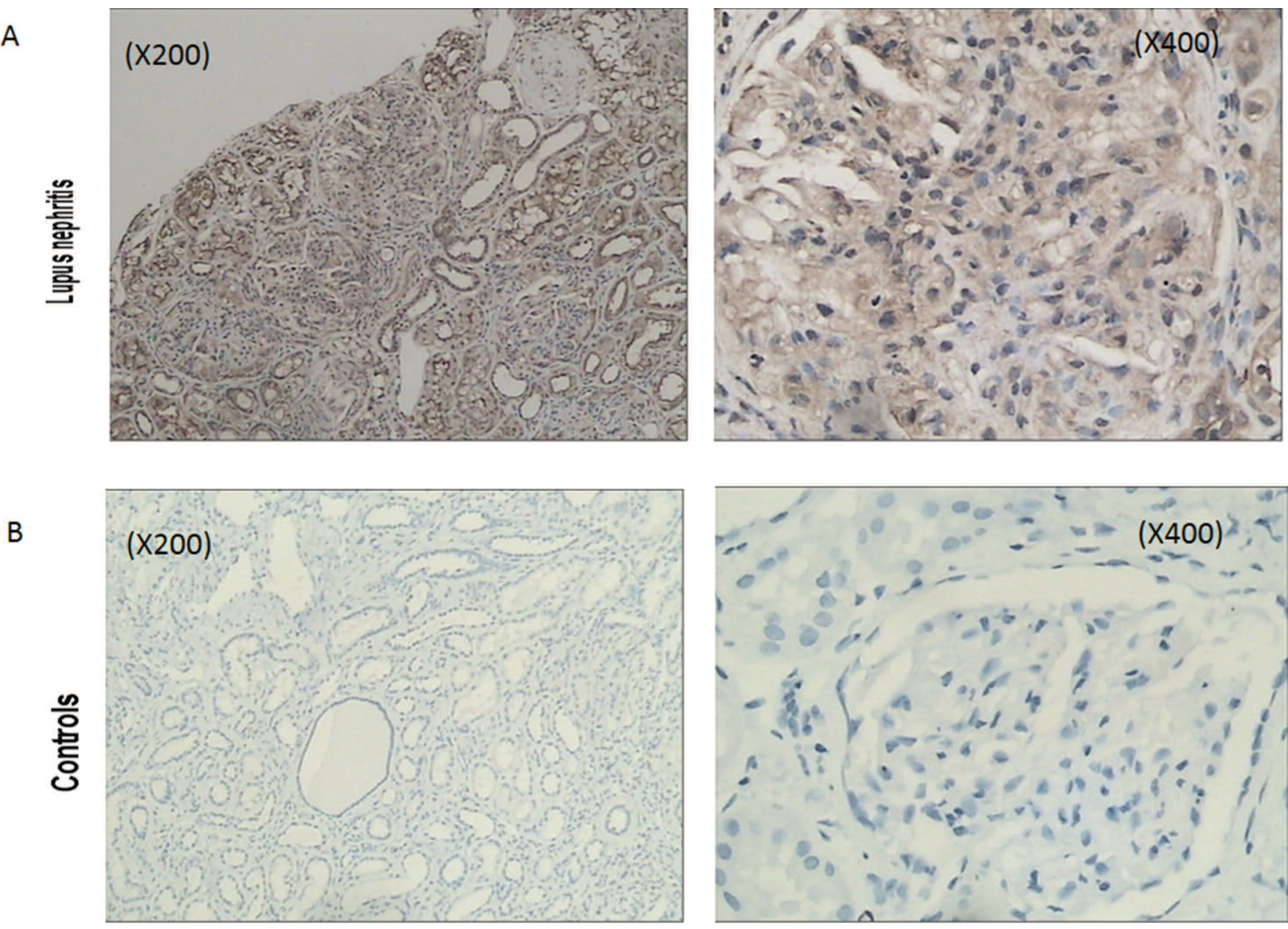

Figure 3. Expression of interleukin 22BP in kidney tissues. Representative immunohistochemistry stainings of kidney section from patients with lupus nephritis (A) and controls (B).

In addition, we could not find a correlation between concentrations of urinary IL-22BP and the levels of anti-dsDNA antibodies in our studied groups. One possible explanation may be the difference in the pathogenic role between them; thus an increase in levels of anti-dsDNA might not coincide with simultaneously higher IL-22BP excretion. Similarly, although the role of complement in LN pathogenesis has been well described ${ }^{36,37}$, in the present study increased urinary IL-22BP was not associated with complement consumption (as measured by low levels of $\mathrm{C} 3$ and $\mathrm{C} 4$ ). In human $\mathrm{LN}$, the timing of a rise in urinary IL-22BP in relation to an increase in anti-dsDNA autoantibodies, decrease in complement, or occurrence of renal flare is still unknown and will need to be established in a longitudinal study. Further, we will need to determine not only whether urinary IL-22BP correlates with measures of disease activity and severity, but also whether its use as an assessment tool is a complement to other nephritis biomarkers such as $\mathrm{C} 3$ and $\mathrm{C} 4$.

We also observed the association between urinary
IL-22BP and treatment response. The levels of urinary IL-22BP in patients with complete response significantly decreased. In contrast, urinary levels of IL-22BP remained unchanged in patients with partial or no response. So, monitoring the value of IL-22BP might be helpful for assessing the condition of active renal disease and consequence of drug therapy.

We describe here the expression of IL-22BP in patients with SLE. These results demonstrated that increased levels of urinary IL-22BP correlated with active renal disease, and urinary IL-22BP might be a novel biomarker for LN.

\section{REFERENCES}

1. Eisenberg R. Mechanisms of autoimmunity. Immunol Res 2003;27:203-18.

2. Kotzin BL. Systemic lupus erythematosus. Cell 1996;85:303-6.

3. Dean GS, Tyrrell-Price J, Crawley E, Isenberg DA. Cytokines and systemic lupus erythematosus. Ann Rheum Dis 2000;59:243-51.

4. Chan RW, Lai FM, Li EK, Tam LS, Chow KM, Li PK, et al. Imbalance of Th1/Th2 transcription factors in patients with lupus nephritis. Rheumatology 2006;45:951-7.

\section{Personal non-commercial use only. The Journal of Rheumatology Copyright @ 2014 . All rights reserved.}




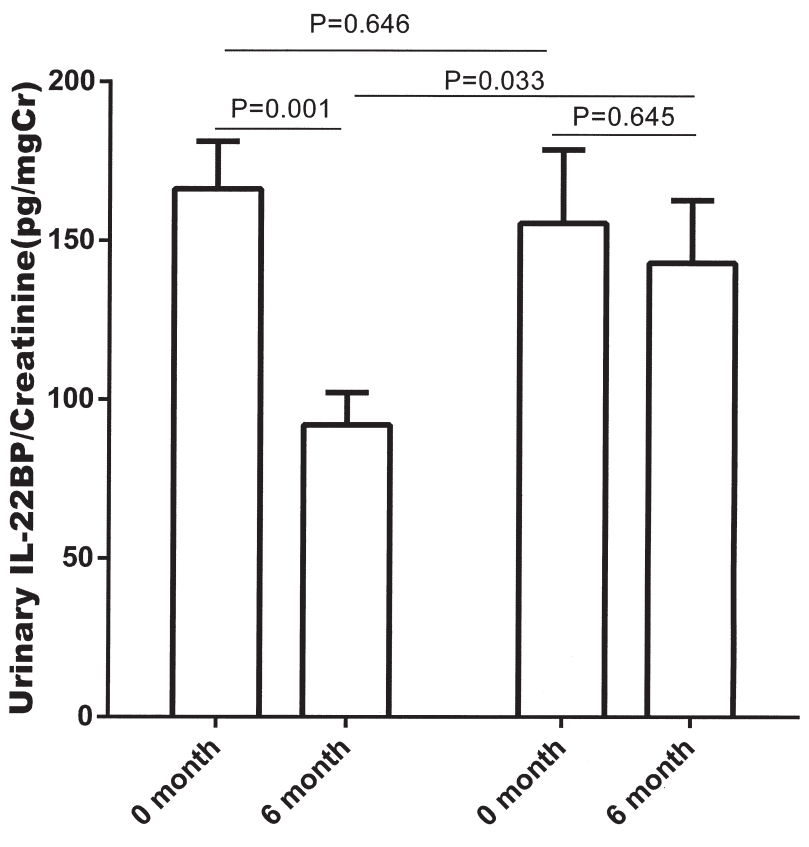

(complete response) (partial or no response)

Figure 4. Comparison of urinary interleukin 22BP (IL-22BP) between patients with different treatment responses. Data before and after treatment are compared by Wilcoxon signed-rank test; data between treatment response groups are compared by Mann-Whitney U test. See Materials and Methods for the definition of therapeutic response. Results for IL-22BP are expressed as picograms of urinary IL-22BP per $\mathrm{mg}$ of creatinine ( $\mathrm{pg} / \mathrm{mgCr}$ ). In patients with complete response, urinary levels of IL-22BP significantly decreased. By contrast, urinary levels of IL-22BP remained unchanged in patients with partial or no response.

5. Sonnenberg GF, Fouser LA, Artis D. Border patrol: regulation of immunity, inflammation and tissue homeostasis at barrier surfaces by IL 22. Nat Immunol 2011;12:383-90.

6. Duhen T, Geiger R, Jarrossay D, Lanzavecchia A, Sallusto F. Production of interleukin-22 but not interleukin-17 by a subset of human skin-homing memory T cells. Nat Immunol 2009;10:857-63.

7. Trifari S, Kaplan CD, Tran EH, Crellin NK, Spits H. Identification of a human helper $\mathrm{T}$ cell population that has abundant production of interleukin 22 and is distinct from $\mathrm{T}(\mathrm{H})-17, \mathrm{~T}(\mathrm{H}) 1$ and $\mathrm{T}(\mathrm{H}) 2$ cells. Nat Immunol 2009;10:864-71.

8. Witte E, Witte K, Warszawska K, Sabat R, Wolk K. Interleukin-22: a cytokine produced by T NK and NKT cell subsets, with importance in the innate immune defense and tissue protection. Cytokine Growth Factor Rev 2010;21:365-79.

9. Sugimoto K, Ogawa A, Mizoguchi E, Shimomura Y, Andoh A, Bhan AK, et al. IL-22 ameliorates intestinal inflammation in a mouse model of ulcerative colitis. J Clin Invest 2008;118:534-44.

10. Pickert G, Neufert C, Leppkes M, Zheng Y, Wittkopf N, Warntjen $\mathrm{M}$, et al. STAT3 links IL-22 signaling in intestinal epithelial cells to mucosal wound healing. J Exp Med 2009;206:1465-72.

11. Zenewicz LA, Yancopoulos GD, Valenzuela DM, Murphy AJ, Stevens S, Flavell RA. Innate and adaptive interleukin-22 protects mice from inflammatory bowel disease. Immunity 2008;29:947-57.

12. Sonnenberg GF, Fouser LA, Artis D. Functional biology of the IL-22-IL-22R pathway in regulating immunity and inflammation at barrier surfaces. Adv Immunol 2010;107:1-29.

13. Ke Y, Sun D, Jiang G, Kaplan HJ, Shao H. IL-22-induced

regulatory CD11b+APCs suppress experimental autoimmune uveitis. J Immunol 2011;187:2130-9.

14. Pan HF, Zhao XF, Yuan H, Zhang WH, Li XP, Wang GH, et al. Decreased serum IL-22 levels in patients with systemic lupus erythematosus. Clin Chim Acta 2009;401 Part 1-2:179-80.

15. Yang XY, Wang HY, Zhao XY, Wang LJ, Lv QH, Wang QQ. Th22, but not Th17 might be a good index to predict the tissue involvement of systemic lupus erythematosus. J Clin Immunol 2013;33:767-74.

16. Dumoutier L, Lejeune D, Colau D, Renauld JC. Cloning and characterization of IL-22 binding protein, a natural antagonist of IL-10-related T cell-derived inducible factor/IL-22. J Immunol 2001;166:7090-5

17. Kotenko SV, Izotova LS, Mirochnitchenko OV, Esterova E, Dickensheets H, Donnelly RP, et al. Identification, cloning, and characterization of a novel soluble receptor that binds IL-22 and neutralizes its activity. J Immunol 2001;166:7096-103.

18. Wei CC, Ho TW, Liang WG, Chen GY, Chang MS. Cloning and characterization of mouse IL-22 binding protein. Genes Immun 2003;4:204-11.

19. Wilson MS, Feng CG, Barber DL, Yarovinsky F, Cheever AW, Sher A, et al. Redundant and pathogenic roles for IL-22 in mycobacterial, protozoan, and helminth infections. J Immunol 2010;184:4378-90.

20. Wolk K, Witte E, Hoffmann U, Doecke WD, Endesfelder S, Asadullah K, et al. IL-22 induces lipopolysaccharide-binding protein in hepatocytes: a potential systemic role of IL-22 in Crohn's disease. J Immunol 2007;178:5973-81.

21. Hochberg M. Updating the American College of Rheumatology revised criteria for the classification of systemic lupus erythematosus. Arthritis Rheum 1997;40:1725-34.

22. Gladman DD, Ibanez D, Urowitz MB. Systemic Lupus Erythematosus Disease Activity Index 2000. J Rheumatol 2002;29:288-91.

23. Bombardier C, Gladman DD, Urowitz MB, Caron D, Chang CH. Derivation of the SLEDAI. Arthritis Rheum 1992;35:630-40.

24. Hernandez-Cruz B, Tapia N, Villa-Romero AR, Reyes E, Cardiel MH. Risk factors associated with mortality in systemic lupus erythematosus. A case-control study in a tertiary care center in Mexico City. Clin Exp Rheumatol 2001;19:395-401.

25. Schiffenbauer J, Simon LS. Randomized controlled trials in systemic lupus erythematosus: what has been done and what do we need to do? Lupus 2004;13:398-405.

26. Petri M, Kasitanon N, Lee SS, Link K, Magder L, Bae SC, et al. Systemic Lupus International Collaborating Clinics renal activity/response exercise: Development of a renal activity score and renal response index. Arthritis Rheum 2008;58:1784-8.

27. Pitashny M, Schwartz N, Qing X, Hojaili B, Aranow C, Mackay M, et al. Urinary lipocalin-2 is associated with renal disease activity in human lupus nephritis. Arthritis Rheum 2007;56:1894-903.

28. Chan TM, Li FK, Tang CS, Wong RW, Fang GX, Ji YL, et al. Efficacy of mycophenolate mofetil in patients with diffuse proliferative lupus nephritis. Hong Kong-Guangzhou Nephrology Study Group. N Engl J Med 2000;343:1156-62.

29. Weening JJ, D'Agati VD, Schwartz MM, Seshan SV, Alpers CE, Appel GB, et al. The classification of glomerulonephritis in systemic lupus erythematosus revisited. Kidney Int 2004;65:521-30.

30. Grande JP, Balow JE. Renal biopsy in lupus nephritis. Lupus 1998;7:611-17.

31. Piantadosi J, Howlett P, Boland J. Matching the grade correlation coefficient using a copula with maximum disorder. J Ind Manage Optim 2007;3:305-12.

32. Esdaile JM, Joseph L, MacKenzie T, Kashgarian M, Hayslett JP. The benefit of early treatment with immunosuppressive drugs in

Personal non-commercial use only. The Journal of Rheumatology Copyright @ 2014 . All rights reserved. 
lupus nephritis. J Rheumatol 1994;21:2046-51.

33. Illei GG, Tackey E, Lapteva L, Lipsky PE. Biomarkers in systemic lupus erythematosus: II. Markers of disease activity. Arthritis Rheum 2004;50:2048-65.

34. Merrill JT, Buyon JP. The role of biomarkers in the assessment of lupus. Best Pract Res Clin Rheumatol 2005;19:709-26.

35. Liu CC, Manzi S, Ahearn JM. Biomarkers for systemic lupus erythematosus: a review and perspective. Curr Opin Rheumatol 2005;17:543-9.
36. Ho A, Magder LS, Barr SG, Petri M. Decreases in anti-double-stranded DNA levels are associated with concurrent flares in patients with systemic lupus erythematosus. Arthritis Rheum 2001;44:2342-9.

37. Karp DR. Complement and systemic lupus erythematosus. Curr Opin Rheumatol 2005;17:538-42. 